\title{
Survey on common reference intervals for general chemistry analytes in Hong Kong
}

\author{
Toby CH Chan, Chloe M Mak *, Sammy PL Chen, MT Leung, HN Cheung, Daniel CW Leung, HK Lee, \\ Eleanor C Koo, YC Lo
}

\section{A B S T R A C T}

Introduction: Reference intervals (RIs) are essential tool for proper interpretation of results. There is a global trend towards implementing common RIs to avoid confusion and enhance patient management across different laboratories. However, local practices with respect to RIs lack harmonisation.

Methods: We have conducted the first local survey regarding RIs for 14 general chemistry analytes in 10 chemical pathology laboratories that employ four different analytical platforms (Abbott Architect, Beckman Coulter AU, Roche Cobas, and Siemens Dimension EXL). Analytical bias was assessed by an inter-laboratory results comparison of external quality assurance programmes.

Results: Sufficient inter-laboratory and interplatform agreement regarding the 10 analytes (albumin, alanine aminotransferase, aspartate aminotransferase, chloride, gamma-glutamyl transferase, phosphate, potassium, sodium, total protein, and urea) were demonstrated. However, the RIs were heterogeneous across all laboratories, with percentage differences of the upper RI value of up to $47 \%$ for aspartate aminotransferase (absolute difference of $16 \mathrm{U} / \mathrm{L}), 29 \%$ for urea $(1.8 \mathrm{mmol} / \mathrm{L})$, and $18 \%$ for potassium $(0.8 \mathrm{mmol} / \mathrm{L})$. The percentage difference between lower RI values was up to $24 \%$ for urea $(0.6 \mathrm{mmol} / \mathrm{L}), 22 \%$ for phosphate $(0.16$ $\mathrm{mmol} / \mathrm{L})$, and $8 \%$ for total protein $(5 \mathrm{~g} / \mathrm{L})$. The coefficients of variation of the upper RI values of potassium and sodium were 1.2 times and 1.0 times of their corresponding between-subject biological variation, respectively, representing unnecessary variations that are overlooked and unchecked in current practice.

Conclusions: We recommend the use of common RIs for general chemistry analytes in Hong Kong to prevent interpreter confusion, improve electronic data transfer, and unite laboratory practice. This is the first local study on this topic, and our data can lay the groundwork for increasing harmonisation of RIs across more laboratory tests.

Hong Kong Med J 2019;25:295-304

https://doi.org/10.12809/hkmj197943

1,2 TCH Chan, MB, BS

1,2 CM Mak *, PhD, MD

${ }^{2,3}$ SPL Chen, FRCPA, FHKAM (Pathology)

${ }^{3}$ MT Leung, MB, BS

${ }^{3} \mathrm{HN}$ Cheung, MB, ChB, MRCP (UK)

${ }^{2}$ DCW Leung, MSc

${ }^{4} \mathrm{HK}$ Lee, MSc, PhD

${ }^{5} \mathrm{EC}$ Koo, MSc

${ }^{6}$ YC Lo, MSC

Chemical Pathology Laboratory, Department of Pathology, Hong Kong Children's Hospital, Kowloon Bay, Hong Kong

2 Chemical Pathology Laboratory, Department of Pathology, Princess Margaret Hospital, Laichikok, Hong Kong

${ }^{3}$ Chemical Pathology Laboratory, Department of Pathology, Queen Elizabeth Hospital, Jordan, Hong Kong

${ }^{4}$ Chemical Pathology Laboratory, Department of Pathology, Tuen Mun Hospital, Tuen Mun, Hong Kong

${ }^{5}$ Clinical Pathology Laboratory, Grantham Hospital, Wong Chuk Hang, Hong Kong

${ }^{6}$ Chemical Pathology Laboratory, Department of Pathology, Pamela Youde Nethersole Eastern Hospital, Chai Wan, Hong Kong

* Corresponding author: makm@ha.org.hk

- Reference intervals (RIs) of general chemistry analytes are highly variable.

- Ten analytes (albumin, alanine aminotransferase, aspartate aminotransferase, chloride, gamma-glutamyl transferase, phosphate, potassium, sodium, total protein, and urea) show satisfactory inter-laboratory and interplatform agreement.

- Implementation of common RIs is feasible.

Implications for clinical practice or policy

- We recommend the use of common RIs in Hong Kong for general chemistry analytes to reduce redundant variation across laboratories.

- This is the first local study on this topic, and our data can lay the groundwork for increasing harmonisation of RIs across more laboratory tests. 


\section{關於香港14種一般化學分析物的參考區間 調查：通用參考區間是否解決方案？}

\section{陳進希、麥苗、陳栢林、梁美廸、張海寧、梁焯華、李漢傑、} 顧惠芬、勞潤泉

引言：參考區間是正確詮釋結果的重要工具。實施通用參考區間是全 球趨勢, 可避免因詮釋引起的混淆並強化不同化驗室的患者管理。然 而，參考區間的使用在本地實踐上仍缺乏一致性。

方法：我們以 10 間化學病理學化驗室的 14 種一般化學分析物進行 首個有關參考區間的本地研究。這些化驗室採用四種不同分析平台 (Abbott Architect、Beckman Coulter AU、Roche Cobas和Siemens Dimension EXL），通過外部質量保證計劃（EQAP）的跨化驗室結 果比較評估分析偏差。

結果：其中 10 種分析物（白蛋白、谷丙轉氨酶ALT、天冬氨酸氨基轉 移酶AST、氯化物、 $\gamma$-谷氨酰轉移酶、磷酸鹽、鉀、鈉、總蛋白和尿 素 ）充份達到跨化驗室和跨平台一致性。然而, 所有化驗室採用的 參考區間皆有差別。在不同化驗室之間, AST參考區間上限的百份比 差異可達47\%（絕對差異 $16 \mathrm{U} / \mathrm{L}$ ），尿素為29\%（1.8 mmol/L ） 鉀為 18\%（0.8 mmol/L ）。尿素參考區間下限的百份比差異可達 $24 \%$ $(0.6 \mathrm{mmol} / \mathrm{L})$, 磷酸鹽為 $22 \%(0.16 \mathrm{mmol} / \mathrm{L})$, 總蛋白質為 $8 \%$ $(5 \mathrm{~g} / \mathrm{L}) \circ$ 鉀和鈉參考區間上限值的變異係數分別是它們相應受試者 間生物學變異的 1.2 倍和 1.0 倍, 突顯出化驗室間參考區間差別的不必 要性

結論：我們建議在香港為一般化學分析物訂立通用參考區間。這可避 免因參考區間不同而引起的詮釋混亂、改善電子數據傳輸並統一化驗 室做法。這些本地研究數據可為更多化驗室測試的參考區間統一化奠 定基礎。

\section{Introduction}

Reference intervals (RIs) are an indispensable tool for clinical decision making in the interpretation of numerical pathology results. Simple yet elegant comparisons with reference subjects empower the interpreter with objective judgements and aid clinicians in diagnosis, treatment, monitoring, prognostication, and screening. ${ }^{1}$

Reference intervals are commonly defined as limiting values, usually upper and lower limits, between which a prespecified percentage (usually 95\%) of results would fall. ${ }^{2,3}$ In daily practice, for most tests, there exists some degree of laboratoryspecific bias related to differences in pre-analytical and analytical factors, such as the choices of analytical platform, methodology, and reagent. Therefore, it is desirable for laboratories to provide sets of laboratory-specific RIs following Clinical and Laboratory Standards Institute guideline C28A3c. A laboratory may establish a new set of RIs by conducting an RI study with at least 120 reference individuals from each subgroup stratified by sex, age, and other parameters as appropriate. ${ }^{2}$ Conducting an RI study is challenging, as enormous efforts of human and financial resources are needed. As the list of analytes is long, it is almost impossible for every laboratory to repeat an RI study to accommodate future changes in methodology or analytical platforms. ${ }^{2,4}$ Alternatively, a laboratory may adopt the RIs established by other sources such as manufacturers or the literature and validate them with at least 20 reference individuals' results. An additional option is for the laboratory to transfer previously established RIs according to mathematical formulas to account for differences in analytical factors. ${ }^{2}$ These methods ensure that each laboratory provides a set of clinically meaningful intervals to clinicians, aiding their management.

Therefore, for the same analyte, it is not uncommon to see different RIs across laboratories. This inter-laboratory coefficient of variation was reported by Ceriotti et $\mathrm{al}^{3}$ to be as high as $15 \%$ to $20 \%$ for the RIs of urea and creatinine. This could be reasonable for hormonal tests that are not optimally standardised, as demonstrated by the marked variations in RIs for thyroid hormones between four analytical platforms shown by a recent study in the UK. ${ }^{5}$ For analytes that are generally well standardised across platforms, such as plasma electrolytes, one would expect results generated by different laboratories to be comparable. Logically, with insignificant methodological bias, the RIs should be same for the specified homogenous population.

In 2007, the UK Pathology Harmony Group showed that laboratories were using different sets of Rls with no sound scientific basis despite using the same analytical platform and reagents. ${ }^{6,7}$ The same problem was later also revealed by a survey on RIs in Australasia. ${ }^{8}$ The differences in RIs were concluded to be unnecessary and would have created unneeded confusion during interpretation, which might lead to inappropriate investigations or treatments. ${ }^{9,10}$ Common RIs were offered as a solution to unite laboratory practices. ${ }^{4}$

In Hong Kong, we have observed a general trend of variation in RIs that resembles those in the UK and Australasia, with various RIs adopted for most tests, including general chemistry laboratory tests. Hence, we conducted the first local study to explore the situation with a territory-wide survey on RIs. The aim was to scientifically review the analytical variation of general chemistry laboratory tests between local laboratories and to examine the evidence for such variations.

\section{Methods}

Fourteen blood general chemistry analytes were included in this study, namely albumin, alanine aminotransferase (ALT), aspartate aminotransferase (AST), alkaline phosphatase (ALP), total bilirubin, calcium, chloride, creatinine, gamma-glutamyl transferase (GGT), phosphate, potassium, sodium, total protein, and urea. We conducted a territory- 
wide survey involving 10 chemical pathology laboratories. All laboratories provided routine services to assess the 14 analytes, except for AST, chloride, and GGT, which were not evaluated in three laboratories. The instruments were Abbott Architect (labs 1-3), Beckman Coulter AU (labs 4-5), Roche Cobas (labs 6-9), and Siemens Dimension EXL (lab 10). Table 1 summarises the analytical platforms and methodologies.

The laboratories participated in the Condensed General Chemistry Programme provided by the Royal College of Pathologists of Australasia Quality Assurance Programs. In each cycle of the external quality assurance programme (EQAP), identical sets of QAP materials were analysed by each individual laboratory for the aforementioned blood general chemistry analytes using their own analytical platform. The use of QAP materials, which were commutable samples with the same properties as routinely analysed clinical samples, minimises the matrix effect. In routine clinical practice, EQAP safeguards laboratory performance by comparison with peers and reference methods. In the present study, we retrospectively review these readily available EQAP data from local laboratories for bias assessments. The participants provided their responses by email to the following items: (1) historical EQAP results of six cycles (105-11, $105-12,105-15,105-16,106-03$, and 106-04); (2) adult RIs in use for clinical service, and (3) analytical specification of assays.

Laboratory performance bias was assessed by percentage differences of EQAP results. Percentage difference was defined as the laboratory result minus the target value divided by the target value. The feasibility of applying common RIs among the laboratories was determined by the degree of agreement between the percentage differences and the corresponding allowable limits of performance. ${ }^{11}$ Data analyses were performed using Microsoft Excel 2016.

\section{Results}

Figure 1 shows that half of the 14 analytes showed agreement across all laboratories. The interlaboratory differences are within the corresponding target allowable limit of error (ALE) for AST (-3\% to $+9 \%$; target ALE $\pm 12 \%)$, chloride $(-1 \%$ to $+2 \% ; \pm 3 \%)$, phosphate $(-1 \%$ to $4 \% ; \pm 8 \%)$, potassium $(-2 \%$ to $3 \%$; $\pm 5 \%)$, sodium ( $-1 \%$ to $2 \% ; \pm 2 \%)$. Three other analytes (albumin, ALT, and GGT) also showed agreement

TABLE I. Summary of analytical platform and methodology

\begin{tabular}{|c|c|c|c|c|c|c|c|c|c|c|}
\hline Analyte & Lab 1 & Lab 2 & Lab 3 & Lab 4 & Lab 5 & Lab 6 & Lab 7 & Lab 8 & Lab 9 & Lab 10 \\
\hline $\begin{array}{l}\text { Analytical } \\
\text { platform }\end{array}$ & \multicolumn{3}{|c|}{ Abbott Architect } & \multicolumn{2}{|c|}{ Beckman Coulter AU } & \multicolumn{4}{|c|}{ Roche Cobas } & $\begin{array}{c}\text { Siemens } \\
\text { Dimension EXL }\end{array}$ \\
\hline Albumin & \multicolumn{5}{|c|}{ BCG } & & & $\mathrm{BCP}$ & $B C G$ & $\mathrm{BCP}$ \\
\hline ALP & AMP buffe & ate (IFCC) & $\begin{array}{l}\text { AMP buffer } \\
\text { (other rate } \\
\text { reaction) }\end{array}$ & \multicolumn{6}{|c|}{ AMP buffer rate (IFCC) } & $\begin{array}{l}\text { AMP buffer (other } \\
\text { rate reaction) }\end{array}$ \\
\hline ALT & \multicolumn{3}{|c|}{ IFCC, no P5P } & \multicolumn{2}{|c|}{ IFCC with P5P } & \multicolumn{2}{|c|}{ IFCC, no P5P } & $\begin{array}{l}\text { IFCC with } \\
\text { P5P }\end{array}$ & $\begin{array}{l}\text { IFCC, no } \\
\text { P5P }\end{array}$ & IFCC with P5P \\
\hline AST & $\begin{array}{l}\text { IFCC, no } \\
\text { P5P }\end{array}$ & - & \begin{tabular}{|l} 
IFCC, no \\
P5P
\end{tabular} & $\begin{array}{l}\text { IFCC with } \\
\text { P5P }\end{array}$ & - & \multicolumn{2}{|c|}{ IFCC, no P5P } & - & $\begin{array}{l}\text { IFCC, no } \\
\text { P5P }\end{array}$ & IFCC with P5P \\
\hline Calcium & \multicolumn{3}{|c|}{ Arsenazo dye } & \multicolumn{2}{|c|}{$\begin{array}{c}\text { Cresol complex, no } \\
\text { dialysis }\end{array}$} & \multicolumn{4}{|c|}{ NM-BAPTA } & $\begin{array}{l}\text { Cresol complex, } \\
\text { no dialysis }\end{array}$ \\
\hline Chloride & \multicolumn{7}{|c|}{ Indirect ISE } & - & Indirect ISE & Indirect IMT \\
\hline Creatinine & \multicolumn{3}{|c|}{ Jaffe, kinetic } & Creati & inase & \multicolumn{4}{|c|}{ Jaffe, compensate } & Jaffe, kinetic \\
\hline GGT & \multicolumn{4}{|c|}{ GluCANA (IFCC) } & - & \multicolumn{2}{|c|}{ GluCANA (IFCC) } & - & \multicolumn{2}{|c|}{ GluCANA (IFCC) } \\
\hline Phosphate & \multicolumn{10}{|c|}{ Phosphomolybdate formation } \\
\hline Potassium & \multicolumn{9}{|c|}{ Indirect ISE } & Indirect IMT \\
\hline Sodium & \multicolumn{9}{|c|}{ Indirect ISE } & Indirect IMT \\
\hline Total bilirubin & \multicolumn{3}{|c|}{ Diazonium salt } & $\begin{array}{r}\text { Caffeine } \\
\text { accel }\end{array}$ & $\begin{array}{l}\text { enzoate } \\
\text { rator }\end{array}$ & \multicolumn{4}{|c|}{ Diazonium salt } & $\begin{array}{c}\text { Caffeine benzoate } \\
\text { accelerator }\end{array}$ \\
\hline Total protein & \multicolumn{7}{|c|}{ Biuret, no blank } & \multicolumn{3}{|c|}{ Biuret, no blank } \\
\hline Urea & \multicolumn{10}{|c|}{ Urease } \\
\hline
\end{tabular}

Abbreviations: ALP = alkaline phosphatase; ALT = alanine aminotransferase; AMP = 2-amino-2-methyl- I-propanol; $A S T$ = aspartate aminotransferase; $B C G$ = bromocresol green; BCP = bromocresol purple; Cresol = cresolphthalein; GGT = gamma-glutamyl transferase; GluCANA = L- $\gamma$-glutamyl-3-carboxy-4nitroanilide; IFCC = International Federation of Clinical Chemistry; IMT = integrated multisensory technology; ISE = ion selective electrode; NM-BAPTA = 5-nitro-5'methyl-BAPTA; P5P = pyridoxine 


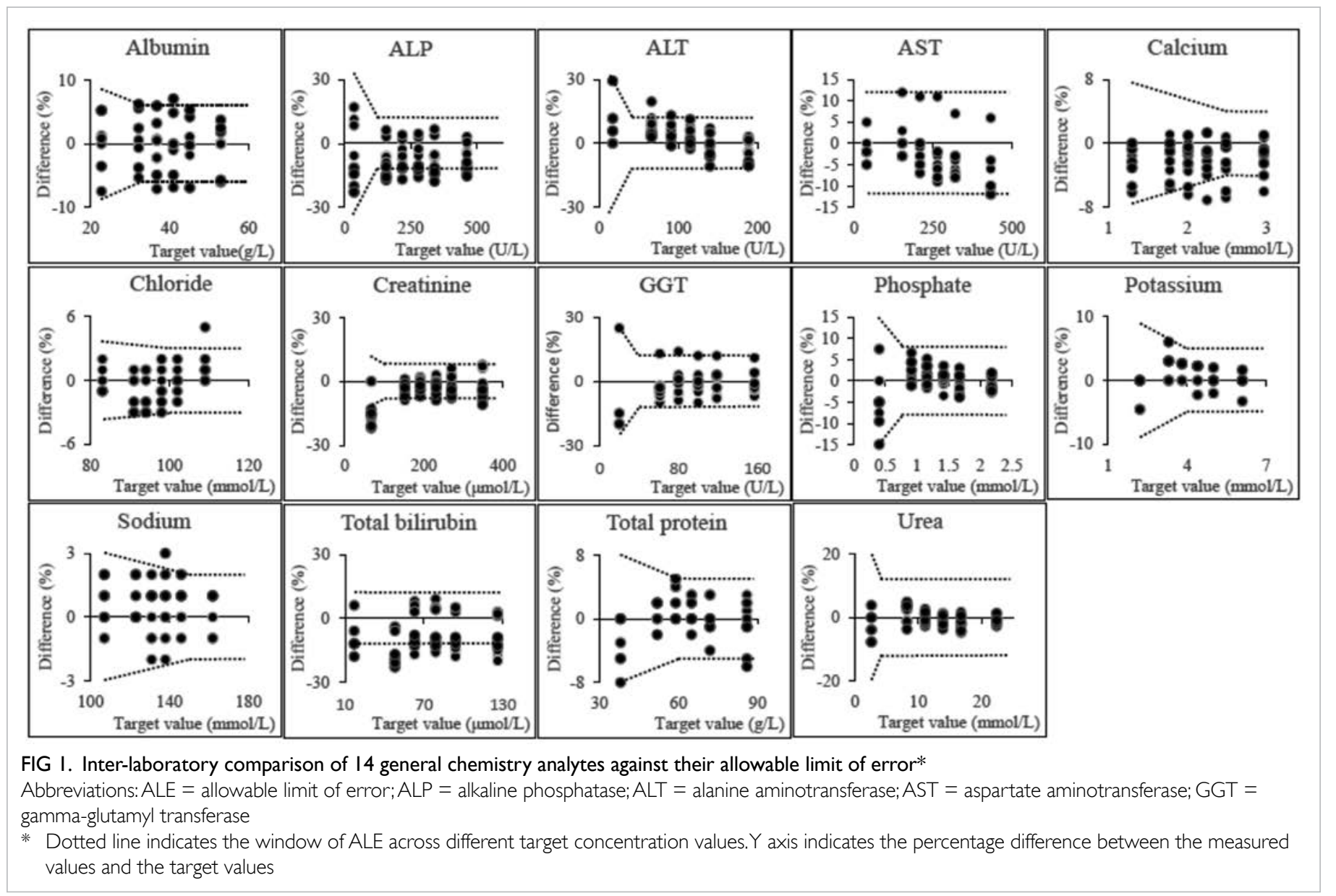

across nine laboratories with the Abbott, Beckman, and Roche platforms, except Siemens which was only used by one laboratory.

Figure 2 shows the inter-laboratory comparison of RIs for the 14 general chemistry analytes. Laboratories using the same platform generally adopted the same RIs, except for one laboratory using the Roche platform.

Notably, for the seven analytes mentioned above that showed agreement within the target ALE, the RIs differed substantially across the 10 laboratories. Particularly, the upper RI limit ranged from 34 to $50 \mathrm{U} / \mathrm{L}$ (coefficient of variation $[\mathrm{CV}]$ : $11 \%)$ : in male samples and 30 to $40 \mathrm{U} / \mathrm{L}(9 \%)$ in female samples in AST; 107 to $109 \mathrm{mmol} / \mathrm{L}(0.9 \%)$ in chloride; 1.39 to $1.52 \mathrm{mmol} / \mathrm{L}$ (2.7\%) in phosphate; 4.4 to $5.2 \mathrm{mmol} / \mathrm{L}(6.7 \%)$ in potassium; 144 to 148 $\mathrm{mmol} / \mathrm{L}(0.7 \%)$ in sodium; 79 to $87 \mathrm{~g} / \mathrm{L}(2.2 \%)$ in total protein; and 6.3 to $8.1 \mathrm{mmol} / \mathrm{L}(8.1 \%)$ in urea. The lower RIs ranged from 98 to $102 \mathrm{mmol} / \mathrm{L}$ (1.7\%) in chloride; 0.72 to $0.88 \mathrm{mmol} / \mathrm{L}(6.2 \%)$ in phosphate; 3.4 to $3.6 \mathrm{mmol} / \mathrm{L}(2.6 \%)$ in potassium; 136 to 137 $\mathrm{mmol} / \mathrm{L}(0.2 \%)$ in sodium; 63 to $68 \mathrm{~g} / \mathrm{L}(2.2 \%)$ in total protein; and 2.5 to $3.1 \mathrm{mmol} / \mathrm{L}(7.4 \%)$ in urea.

The remaining analytes (albumin, ALT, ALP,

calcium, creatinine, GGT, and total bilirubin) demonstrated substantial platform-specific bias exceeding the target ALE. High bias exceeding the ALE was observed for ALT $(+12 \%$ to $+20 \%$; target ALE $\pm 12 \%)$ and GGT $(+11 \%$ to $+14 \% ; \pm 12 \%)$, with negative bias exceeding the ALE in albumin $(-5.3 \%$ to $-7.1 \% ; \pm 6 \%)$, ALP $(-11.4 \%$ to $-15.3 \% ; \pm 12 \%)$, and calcium $(-5.6 \%$ to $-7.1 \% ; \pm 4 \%)$ present on the Siemens platform. Negative bias exceeding the ALE in ALP $(-12.2 \%$ to $-14.8 \% ; \pm 12 \%)$ was also detected on the Roche platform. For calcium, negative bias exceeding the ALE $(-4 \%$ to $-6 \% ; \pm 4 \%)$ was also detected at one laboratory using the Beckman platform. For creatinine, all laboratories were in agreement about concentrations ranging from 152 to $349 \mu \mathrm{mol} / \mathrm{L}$. However, significant negative bias $(-13 \%$ to $-22 \%$; $\pm 12 \%)$ was observed for creatinine levels at the target value of $67 \mu \mathrm{mol} / \mathrm{L}$ on the Abbott, Siemens, and Roche instruments. For total bilirubin, half of the laboratories showed agreement within the ALE, while the remaining laboratories had significant negative bias $(-14 \%$ to $17 \% ; \pm 12 \%)$.

The investigated laboratories used different RIs despite employing the same analytical platforms, methods and reagents, for 11 out of the 14 analytes 


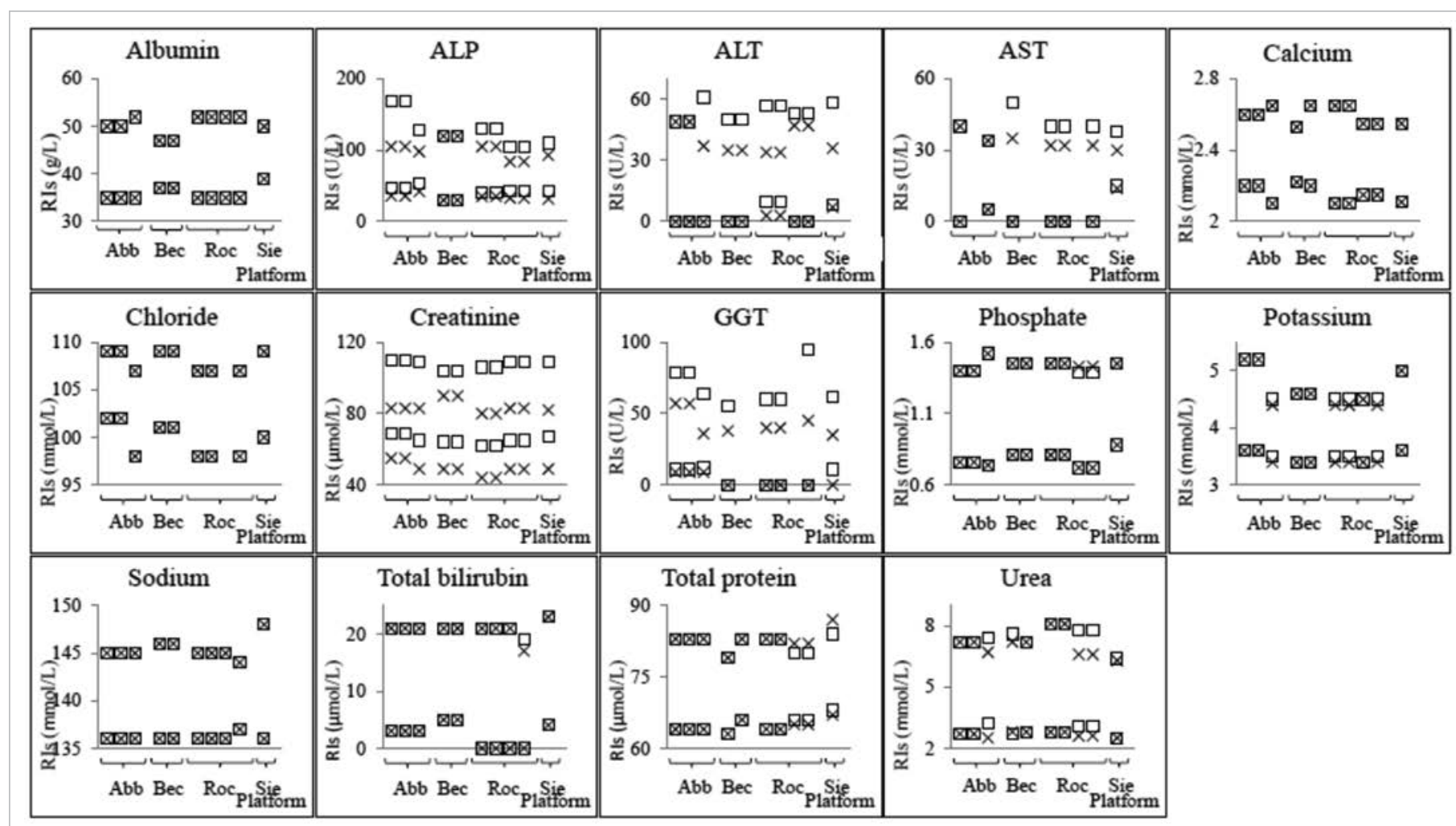

FIG 2. Inter-laboratory reference intervals of the 14 analytes among the four analytical platforms*

Abbreviations: $\mathrm{Abb}=$ Abbott Architect; ALP = alkaline phosphatase; ALT = alanine aminotransferase; $A S T=$ aspartate aminotransferase; Bec = Beckman Coulter AU; GGT = gamma-glutamyl transferase; Rls = reference intervals; Roc = Roche Cobas; Sie = Siemens Dimension EXL

* The Y-axis refers to the upper and lower RI limits, with square and cross symbols representing those of male and female samples, respectively. The X-axis lists the laboratories in ascending nominal order (ie, labs I-10) from left to right. Laboratories employing the same analytical platform are highlighted by brackets

among those using the Abbott platform (labs 1-3), 11 out of 14 of analytes among those using Roche platforms (labs 6-9), and three out of the 14 of analytes among those using the Beckman platforms (labs 4-5).

Sex-specific RIs were not consistently provided for eight analytes (ALP, ALT, AST, phosphate, potassium, total bilirubin, total protein, and urea). For instance, sex-specific RIs were not provided by two laboratories for ALP, two for ALT, two for AST, five for potassium, five for urea, seven for total protein, eight for phosphate, and nine for total bilirubin.

\section{Discussion}

Reference intervals are provided by laboratories as interpretative tools to aid clinical decision making. Theoretically, RIs could be affected by patient factors (eg, sex, age, ethnicity, biological variability), preanalytical and analytical factors (eg, choice of method, reagents, platform, calibration), and statistical methodology. ${ }^{12}$ Therefore, for the same population, the RIs used for a test are inevitably influenced by the bias of the laboratory assays. In other words, RIs should theoretically be the same if the above-listed factors do not introduce significant bias.

In local practice, 10 analytes surveyed demonstrated sufficient agreement within the ALE between different analytical platforms across laboratories (Fig 1: AST, chloride, phosphate, potassium, sodium, total protein, and urea for all four platforms; albumin, ALT and GGT for Abbott, Beckman, and Roche platforms) [Fig 1]. These results confirmed the previous findings of bias assessment by the Australasian Association of Clinical Biochemists, which concluded that chloride, phosphate, potassium, sodium, total protein, and urea measurements showed sufficient similarity across analytical platforms and laboratories and that common RIs could be adopted. ${ }^{10}$ The same study found method-specific bias in AST levels averaging $+22 \%$ for assays using pyridoxal-5-phosphate as an activator compared with those not using pyridoxal5-phosphate. ${ }^{10}$ Our results showed a lesser degree of pyridoxal-5-phosphate-related bias $(+7 \%)$, so this issue would not prevent the use of common RIs in the local scenario. 
For analytes with demonstrated agreement across platforms and laboratories, the RIs are theoretically expected to be the same if obtained from the same group of reference (ie, 'healthy') individuals. In actual practice, for the seven analytes mentioned above, all of the adult RIs varied across laboratories, with the CV of the upper and lower limits of the RIs up to $11 \%$ and $7.4 \%$, respectively. The inter-laboratory percentage differences of upper RI limits were up to $47 \%$ for AST (absolute difference: $16 \mathrm{U} / \mathrm{L}$ ), $29 \%$ for urea $(1.8 \mathrm{mmol} / \mathrm{L})$, and $18 \%$ for potassium $(0.8$ $\mathrm{mmol} / \mathrm{L}$ ), and those of the lower RI limits were up to $24 \%$ for urea $(0.6 \mathrm{mmol} / \mathrm{L}), 22 \%$ for phosphate $(0.16$ $\mathrm{mmol} / \mathrm{L})$, and $8 \%$ for total protein $(5 \mathrm{~g} / \mathrm{L})$. We can compare the CVs of these analytes' RIs against the corresponding between-subject biological variation (CV-G) values published by Ricos et al..$^{13}$ The CV of the upper RI limits of potassium and sodium were 1.2 and 1.0 times those of $\mathrm{CV}-\mathrm{G}$, respectively while that of the lower RI limits of sodium and phosphate were 1.1 and 0.6 times those of CV-G, respectively. These RI variations generate significant additional bias during interpretation, which is often overlooked and unchecked. Furthermore, laboratories were using different RIs despite using the same analytical platforms and methodologies for these analytes. For example, among users of the Abbott platform, the potassium RIs of labs 1 and 2 were 3.6 to $5.2 \mathrm{mmol} / \mathrm{L}$ for samples of both sexes, while that of lab 3 was 3.5 to $4.5 \mathrm{mmol} / \mathrm{L}$ for male and 3.4 to $4.4 \mathrm{mmol} / \mathrm{L}$ for female samples. These variations were unnecessary, as supported by the sufficient agreement across analytical platforms and laboratories. Application of different RIs in various circumstances could lead to confusion among interpreters and hinder data management in the era of electronic health records. ${ }^{4,14}$ Similar trends of unexplained RI variations were previously observed in the UK for sodium, potassium, and other analytes, and this eventually lead to the Pathology Harmony group's recommendation of harmonised RIs. ${ }^{7}$ At present, local laboratories often spend substantial human resources on decisions and maintenance regarding the appropriate RIs for large numbers of analytes. The use of common RIs for these seven analytes would unite local laboratory practices, facilitate electronic communications between laboratory information and electronic patient record systems, and streamline the maintenance of RIs.

For creatinine, low bias was noted for seven laboratories using the Jaffe methods, but this tendency spared the laboratories that used the enzymatic method on the Beckman platform. This bias was likely related to the high variability of the Jaffe method at low creatinine concentrations, which has been reported to be up to $30 \%$ on some platforms. ${ }^{15}$ While the remarkably good analytical agreement shown for the remaining five higher concentrations of creatinine support the use of common RIs, this should be cautiously reviewed, as the lowest concentration of creatinine $(67 \mu \mathrm{mol} / \mathrm{L})$ is very close to the lower RI limit. Further study of bias may be warranted for creatinine.

Substantial bias exceeding the ALE was demonstrated for the remaining six analytes, with high bias for ALT and GGT and low bias for albumin, ALP, and calcium on the Siemens platform; low bias for ALP on the Roche platform; low bias for calcium at one laboratory using the Beckman platform; and low bias for total bilirubin in labs 1 to 3,7 , and 8 . Positive bias averaging $8 \%$ for albumin was observed for laboratories using the bromocresol green method compared with the bromocresol purple method, a pattern similar to the findings of Koerbin et al. ${ }^{10,16}$ Bias in ALT measurement could be attributed to differences in assay design, ${ }^{10}$ with an average of $+7 \%$ bias shown for the assay using pyridoxal-5-phosphate over the assay that does not use it. Bias for calcium and total bilirubin could be related to methodological differences between platforms, while bias for ALP and GGT were likely to be specific to the analytical platform. While the feasibility of local common RIs for these six analytes was not confirmed by this study, our findings indicate that common RIs could still be considered for albumin, ALT, and GGT in laboratories using the Abbott, Beckman, and Roche platforms, which all laboratories except one use.

Variable adoptions of sex-specific RIs were another key finding of the survey. Heterogeneous and inconsistent practices of sex partitioning for RIs were noted in eight analytes (ALP, ALT, AST, phosphate, potassium, total bilirubin, total protein, and urea). Moreover, sex-specific RIs were sometimes different even within the same platform. For example, the upper RI limit of GGT in male samples differed by $35 \mathrm{U} / \mathrm{L}$ among users of the Roche platform, and the upper RI limit of ALP differed by $40 \mathrm{U} / \mathrm{L}$ and $7 \mathrm{U} / \mathrm{L}$ in male and female samples, respectively, among users of the Abbott platform. Common RIs with united practice of sex partitioning could be the solution to converge these practices.

Historically, heterogeneous and sometimes incomparable results of the same measurands could be obtained with different assays because of suboptimal standardisations in pre-analytical and analytical factors. Laboratory-specific RIs were advocated to compensate and allow for sound interpretations of laboratory results in clinical settings. ${ }^{17}$ Realising the need for assay standardisation, an enormous global effort has been taken in the past 60 years to study biological variability, standardise pre-analytical conditions and analytical methods, improve quality control, establish traceability of reference materials and methods, and implement EQAPs for various kinds of assays, led by the International Federation of 
Clinical Chemistry (IFCC) and other international/ national organisations. ${ }^{18}$ Major successes have been realised for a large number of measurands, as listed on the website of the International Consortium for Harmonization of Clinical Laboratory Results. ${ }^{19}$

The concept of common RIs emerged in the early 2000s and has gained huge popularity over the past decade. ${ }^{4}$ The theory is simple: if the measured results of different assays are comparable, ie with adequate assay standardisation, the same RIs should be adopted given that the tests are performed on the same reference population. ${ }^{17}$ Redundant variations of RIs merely impair interpretation.

Presently, there are two types of common RIs: 'objective' and 'subjective' ones. ${ }^{20}$ Subjective common RIs were generally defined by scientific surveys and expert guidance with the harmonisation approach. Examples include the "agreed Pathology Harmony clinical biochemistry reference intervals for adults" for 15 general chemistry analytes recommended by the UK Pathology Harmony Group in $2011^{21}$ and the "adult harmonised reference intervals" for 18 general chemistry analytes recommended by the Australasian Association of Clinical Biochemists and endorsed by the Royal College of Pathologists of Australasia in 2016..$^{16,22,23}$ The two groups have since continued their work on harmonisation of various aspects of pathology in the past decade, with the UK Pathology Harmony Group working on the Pathology Harmony bookmark for tumour markers and requesting guidance for non-specialists, and the Australasian Association of Clinical Biochemists working on harmonisation of paediatric common RIs, serum protein electrophoresis reporting, lipid reporting, management and communication of high-risk lab results, arterial and venous blood gas RIs, and reporting of dynamic endocrine testing for adults and paediatric patients..$^{6-8,16,24-26}$

Objective common RIs refer to those defined by well-conducted, multicentre reference studies, such as the Nordic Trueness Project, which was conducted with well-standardised pre-analytical and analytical handlings and the use of five control materials. The project involved 102 Nordic routine clinical biochemistry laboratories and more than 2500 carefully selected healthy reference individuals. ${ }^{27}$ The Nordic Reference Interval Project RIs for 25 general chemistry analytes were established and published in 2002 and implemented throughout Nordic countries in 2004 with the help of the Scandinavian Society of Clinical Chemistry. ${ }^{27-30}$ Among Asian countries, the Japan Society of Clinical Chemistry has recently published their nationwide common RIs for 40 laboratory tests determined by three multicentre RI studies. ${ }^{31}$ Table $2^{8,21,23,28,31}$ summarises the common RIs published in different parts of world for the general chemistry analytes surveyed and the common RIs proposed by our study.

In 2017, the IFCC Committee on Reference Intervals and Decision Limits (C-RIDL) published two landmark papers on the results of their global multicentre study on reference values of 25 chemistry analytes in 13386 healthy adults recruited from 12 countries, including China, ${ }^{32}$ with the use of a specially designed serum panel..$^{33,34}$ The study explored the regionality and ethnicity of these reference values globally and provided invaluable information for the possibility of future derivation and transference of the established RIs through use of the C-RIDL serum panel. ${ }^{34}$

The relatively small number and choice of QAP specimens for retrospective methodological comparisons represent a major limitation of our survey. Artificial materials used in QAP specimens generally gave rise to more variable and methoddependent results due to matrix effects. ${ }^{9}$ Despite this, our survey demonstrated that methodological bias would not prevent the use of common RIs for seven general chemistry analytes. For the remaining analytes, we speculate that the degree of methodological bias may be exaggerated by the matrix effect of the QAP, ie, the actual analytical difference is likely to be smaller when tested with a patient sample. Our findings should be verified with a formal prospective bias study with a standardised protocol and the use of another set of blood specimens, preferably unadulterated human samples, with pre-assigned reference values to ensure commutability.

This survey compared the adult RIs of 14 general chemistry analytes among 10 chemical pathology laboratories using four different analytical platforms. Bias assessments and comparisons of RIs revealed that different and variable RIs were provided by the laboratories despite sufficient inter-laboratory and inter-platform agreement regarding the RIs of 10 general chemistry analytes. The use of common RIs was found to be feasible and is recommended for these 10 analytes. Such use would unify and improve local standards of clinical laboratory practice. A well-designed implementation plan for common RIs with support from stakeholders including clinicians, pathologists, and scientists would be vital for the success of such a substantial project. Figure 3 shows our proposed implementation plan for the introduction of common RIs in Hong Kong, modified from the plan suggested by Tate et $\mathrm{al}^{8}$ for the harmonisation of adult and paediatric RIs in Australasia. Furthermore, the concept of common RIs could be expanded to cover more general chemistry analytes, eg, creatine kinase and magnesium; special chemical tests, eg, therapeutic drug monitoring and hormones; other clinical laboratory specialties, such as haematology and immunology; and paediatric RIs. ${ }^{6-8}$ 
TABLE 2. Summary of adult common reference intervals published in United Kingdom, Australasia, Japan, and Nordic countries

\begin{tabular}{|c|c|c|c|c|c|c|}
\hline Analyte (unit) & Sex & $\begin{array}{l}\text { United } \\
\text { Kingdom }^{21}\end{array}$ & Australasiaa & Japan $^{31}$ & Nordic countries ${ }^{28}$ & $\begin{array}{c}\text { Hong Kong } \\
\text { (proposed by this } \\
\text { study) }\end{array}$ \\
\hline Albumin (g/L) & $\mathrm{M} / \mathrm{F}$ & $35-50$ & - & $41-51$ & $\begin{array}{c}36-48 \text { (18-39 years) } \\
36-45 \text { (40-69 years) } \\
34-45 \text { ( } \geq 70 \text { years) }\end{array}$ & $36-50$ \\
\hline ALP (U/L) & $\mathrm{M} / \mathrm{F}$ & $30-130$ & $30-110$ & $106-322$ & $35-105$ & - \\
\hline \multirow[t]{2}{*}{ ALT (U/L) } & M & - & $5-40$ & $10-42$ & $10-70$ & $<54$ \\
\hline & $\mathrm{F}$ & & $5-35$ & $7-23$ & $10-45$ & $<40$ \\
\hline \multirow[t]{2}{*}{ AST (U/L) } & $M$ & - & $5-35$ & $13-30$ & $15-45$ & $<40$ \\
\hline & $\mathrm{F}$ & & $5-30$ & & $15-35$ & $<34$ \\
\hline Calcium (mmol/L) & $M / F$ & - & $2.1-2.6$ & $2.18-2.52$ & $2.15-2.51$ & - \\
\hline Chloride (mmol/L) & $\mathrm{M} / \mathrm{F}$ & $95-108$ & $95-110$ & $101-108$ & - & $100-108$ \\
\hline \multirow[t]{2}{*}{ Creatinine $(\mu \mathrm{mol} / \mathrm{L})$} & M & - & $60-110$ & $58-94$ & $60-110$ & - \\
\hline & $\mathrm{F}$ & & $45-90$ & $41-70$ & $50-90$ & \\
\hline \multirow[t]{2}{*}{ GGT (U/L) } & M & - & $5-50$ & $13-64$ & $\begin{array}{l}10-80 \text { (18-39 years) } \\
15-115 \text { ( } \geq 40 \text { years) }\end{array}$ & $6-69$ \\
\hline & $\mathrm{F}$ & & $5-35$ & $9-32$ & $\begin{array}{c}10-45 \text { ( } 18-39 \text { years) } \\
10-75 \text { ( } \geq 40 \text { years) }\end{array}$ & $3-44$ \\
\hline Phosphate (mmol/L) & $M / F$ & $0.8-1.5$ & $0.75-1.5$ & $0.9-1.5$ & $\begin{array}{c}\text { For males: } \\
0.71-1.53 \text { (18-49 years, plasma) } \\
0.75-1.65 \text { (18-49 years, serum) } \\
0.71-1.23 \text { ( } \geq 50 \text { years, plasma) } \\
0.71-1.35 \text { ( } \geq 50 \text { years, serum) } \\
\text { For females: } \\
0.79-1.41 \text { (plasma) } \\
0.85-1.50 \text { (serum) }\end{array}$ & $0.78-1.44$ \\
\hline Potassium (mmol/L) & $\mathrm{M} / \mathrm{F}$ & $3.5-5.3$ & $3.5-5.2$ & $3.6-4.8$ & 3.5-4.4 (plasma), 3.6-4.6 (serum) & $3.5-4.7$ \\
\hline Sodium (mmol/L) & $M / F$ & $133-146$ & $135-145$ & $138-145$ & 137-144 (plasma), 137-145 (serum) & $136-145$ \\
\hline Total bilirubin ( $\mu \mathrm{mol} / \mathrm{L})$ & $\mathrm{M} / \mathrm{F}$ & $<21$ & $1-20$ & - & $5-25$ & - \\
\hline Total protein (g/L) & $M / F$ & $60-80$ & $60-80$ & $66-81$ & 64-79 (plasma), 62-78 (serum) & $65-83$ \\
\hline Urea (mmol/L) & $\mathrm{M} / \mathrm{F}$ & $2.5-7.8$ & - & $2.7-7.1$ & - & $2.7-7.5$ \\
\hline
\end{tabular}

Abbreviations: ALP = alkaline phosphatase; ALT = alanine aminotransferase; AST = aspartate aminotransferase; GGT = gamma-glutamyl transferase 


\section{Author contributions}

All authors contributed to the concept or design, drafting of the article, and critical revision for important intellectual content. All authors had full access to the data, contributed to the study, approved the final version for publication, and take responsibility for its accuracy and integrity.

\section{Conflicts of interest}

All authors have disclosed no conflicts of interest.

\section{Funding/support}

This research received no specific grant from any funding agency in the public, commercial, or not-for-profit sectors.

\section{Ethics approval}

The present survey is a retrospective observational review of local laboratory practice and external quality assurance program data with no patient participation, no access to private or sensitive patient data, no collection or analysis of human body fluid or tissue. The quality assurance program materials used for the data collection in the survey are processed samples designed by the external quality assurance program organiser to mimic the properties of clinical sample. Therefore, ethics approval was not applicable for this study.

\section{References}

1. Plebani M, Lippi G. Reference values and the journal: why the past is now present. Clin Chem Lab Med 2012;50:7613.

2. Defining, Establishing, and Verifying Reference Intervals in the Clinical Laboratory; Approved Guideline-Third Edition. Clinical and Laboratory Standards Institute; 2010.

3. Ceriotti F, Hinzmann R, Panteghini M. Reference intervals: the way forward. Ann Clin Biochem 2009;46:8-17.

4. Jones GR, Barker A, Tate J, Lim CF, Robertson K. The case for common reference intervals. Clin Biochem Rev 2004;25:99-104.

5. Barth JH, Luvai A, Jassam N, et al. Comparison of methodrelated reference intervals for thyroid hormones: studies from a prospective reference population and a literature review. Ann Clin Biochem 2018;55:107-12.

6. Berg J. The approach to pathology harmony in the UK. Clin Biochem Rev 2012;33:89-93.

7. Berg J. The UK Pathology Harmony initiative; The foundation of a global model. Clin Chim Acta 2014;432:226.

8. Tate JR, Sikaris KA, Jones GR, et al. Harmonising adult and paediatric reference intervals in Australia and New Zealand: an evidence-based approach for establishing a first panel of chemistry analytes. Clin Biochem Rev 2014;35:213-35.

9. Jones G, Barker A. Standardisation of reference intervals: an Australasian view. Clin Biochem Rev 2007;28:169-73.

10. Koerbin G, Tate JR, Ryan J, et al. Bias assessment of general chemistry analytes using commutable samples. Clin Biochem Rev 2014;35:203-11.

11. Jones GR, Sikaris K, Gill J. 'Allowable limits of performance' for external quality assurance programs-an approach to application of the Stockholm Criteria by the RCPA Quality Assurance Programs. Clin Biochem Rev 2012;33:133-9.

12. Ozarda Y. Reference intervals: current status, recent developments and future considerations. Biochem Med (Zagreb) 2016;26:5-16.

13. Ricós C, Alvarez V, Cava F, et al. Current databases on biological variation: pros, cons and progress. Scand J Clin Lab Invest 1999;59:491-500.

14. Koerbin G, Sikaris KA, Jones GR, et al. Evidence-based approach to harmonised reference intervals. Clin Chim Acta 2014;432:99-107.

15. Hoste L, Deiteren K, Pottel H, Callewaert N, Martens F. Routine serum creatinine measurements: how well do we perform? BMC Nephrol 2015;16:21.

16. Koerbin G, Sikaris K, Jones GR, et al. An update report on the harmonization of adult reference intervals in Australasia. Clin Chem Lab Med 2018;57:38-41.

17. Ceriotti F. Prerequisites for use of common reference intervals. Clin Biochem Rev 2007;28:115-21.

18. Siest G, Henny J, Gräsbeck R, et al. The theory of reference values: an unfinished symphony. Clin Chem Lab Med 2013;51:47-64.

19. International Consortium for Harmonization of Clinical Laboratory Results. Summary of measurand harmonization activities. Available from: www.harmonization.net/ measurands/. Accessed 27 Mar 2019.

20. Ozarda Y, Sikaris K, Streichert T, Macri J; IFCC Committee on Reference Intervals and Decision Limits (C-RIDL). Distinguishing reference intervals and clinical decision limits-a review by the IFCC Committee on Reference Intervals and Decision Limits. Crit Rev Clin Lab Sci 2018;55:420-31.

21. Berg J, Lane V. Pathology Harmony; a pragmatic and scientific approach to unfounded variation in the clinical laboratory. Ann Clin Biochem 2011;48(Pt 3):195-7.

22. Jones GR, Koetsier S. Uptake of recommended common reference intervals for chemical pathology in Australia. Ann Clin Biochem 2017;54:395-7.

23. Koerbin G, Tate JR. Harmonising adult reference intervals in Australia and New Zealand-the continuing story. Clin Biochem Rev 2016;37:121-9.

24. Campbell C, Caldwell G, Coates P, et al. Consensus statement for the management and communication of high risk laboratory results. Clin Biochem Rev 2015;36:97105.

25. Tate J, Caldwell G, Daly J, et al. Recommendations for standardized reporting of protein electrophoresis in Australia and New Zealand. Ann Clin Biochem 2012;49:242-56.

26. Australasian Association of Clinical Biochemists. Harmonisation: guideline, publications, history, committee. Available from: www.aacb.asn.au/aboutus/ harmonisation. Accessed 27 Mar 2019.

27. Pedersen MM, Ornemark U, Rustad P, et al. The Nordic Trueness Project 2002: use of reference measurement procedure values in a general clinical chemistry survey. Scand J Clin Lab Invest 2004;64:309-20.

28. Rustad P, Felding P, Franzson L, et al. The Nordic Reference Interval Project 2000: recommended reference intervals for 25 common biochemical properties. Scand J Clin Lab Invest 2004;64:271-84.

29. Strømme JH, Rustad P, Steensland H, Theodorsen L, Urdal P. Reference intervals for eight enzymes in blood of adult females and males measured in accordance with the International Federation of Clinical Chemistry reference system at 37 degrees C: part of the Nordic Reference 
Interval Project. Scand J Clin Lab Invest 2004;64:371-84.

30. Rustad P, Felding P, Lahti A, Hyltoft Petersen P. Descriptive analytical data and consequences for calculation of common reference intervals in the Nordic Reference Interval Project 2000. Scand J Clin Lab Invest 2004;64:343-70.

31. Ichihara K, Yomamoto Y, Hotta T, et al. Collaborative derivation of reference intervals for major clinical laboratory tests in Japan. Ann Clin Biochem 2016;53:34756.

32. Xia L, Chen M, Liu M, et al. Nationwide multicenter reference interval study for 28 common biochemical analytes in China. Medicine (Baltimore) 2016;95:e2915.

33. Ichihara K, Ozarda Y, Barth JH, et al. A global multicenter study on reference values: 1 . Assessment of methods for derivation and comparison of reference intervals. Clin Chim Acta 2017;467:70-82.

34. Ichihara K, Ozarda Y, Barth JH, et al. A global multicenter study on reference values: 2. Exploration of sources of variation across the countries. Clin Chim Acta 2017;467:8397. 